\title{
THEORETICAL ANALYSIS OF THE ROLLING PROCESS OF A THICK-WALLED THIMBLE IN AN ELONGATING MILL
}

\author{
Jesica BIŚ, Bartosz KOCZURKIEWICZ, Marcin KWAPISZ
}

Częstochowa University of Technology, Częstochowa, Poland, EU, kuras.jesica@wip.pcz.pl

https://doi.org/10.37904/metal.2019.821

\begin{abstract}
The technological process of rolling of seamless tube consists of three stages. In the first of them, a thimble shaped hollow is produced from the cast ingot (usually square), which in the second stage is rolled into the thimble. The next part of the manufacturing process is the main rolling on the mandrel, where intensive elongation is associated with the reduction of the cross-section. The last stage is the reduction rolling or calibration rolling in which the tubular thimble is shaped into a hot rolled tube.

During research carried out in industrial conditions by the researchers of the Institute of Metal Forming and Safety Engineering of the Częstochowa University of Technology, aimed at increasing the efficiency of the tube rolling process in a pilgrim mill, the influence of the technological parameters of rolling on the quality of finished tube and the reduction of technological waste was found. The documentation and analysis recording data have shown that there is a possibility of multi-component adjustment of the extension mill settings affecting the flow behavior in the rolling gap. Proper selection of parameters will allow to control the metal flow behavior of the rolling thimble in a way which improves the quality of tubes manufactured by the pilgrim method.

The paper presents preliminary results of numerical tests on the influence of the rolling process of a thimble in an elongation rolling mill on the material flow. Numerical modeling was carried out using the FORGE 2.1 NxT computer program. Based on results of computer simulations, the distribution of strain intensity and intensity of strain rate was determined. Based on the theoretical tests, it was found that it is possible to select the appropriate technological parameters to ensure a more even flow of material in the rolling gap and to improve the shape of the thimble after being rolled in the extension mill.
\end{abstract}

Keywords: Rolling process, elongating mill, numerical modeling

\section{INTRODUCTION}

One of the most popular methods of pipe rolling is the pilgrim method, which allows the production of pipes from carbon and alloy steel and special alloys with a wide dimensional range of external diameters $D=159 \div$ $710 \mathrm{~mm}$ and wall thicknesses $g=5.0 \div 120 \mathrm{~mm}$. The technological process of rolling seamless pipes in a pilgrim mill can be divided into the following stages:

- $\quad$ puncturing in the presses of ingots with thick-walled sleeves with bottom,

- rolling in an oblique rolling mill extending thick-wall sleeves,

- $\quad$ rolling in a pilgrim mill,

- $\quad$ shaping the tube sleeve into the ready pipe by rolling in rolling mills with tensioning or calibrating.

The research carried out in the Institute of Metal Forming and Safety Engineering of Częstochowa University of Technology aims at modifying the pipe manufacturing process. Thick-walled sleeves with bottom (received in the puncher press) are subjected to a rolling operation in the elongating slant rolling mill (along with the guide). The task of the alongator is to extend the thick-walled sleeves with the bottom obtained in the first stage of processing - when piercing the semi-finished products in the press and the press-roller or punching them in slanting mills [1]. By lengthening the thick-walled thimble (sleeve) during plastic processing, uneven wall thickness on the cross-section is reduced, i.e. the eccentricity of the obtained sleeves is reduced to $70 \%$. 
The axes of each work roll are inclined in the vertical plane of the mill at an angle $\beta$ (Figure 1a), called the bevel of the working roll and inclined in the horizontal plane of the mill at an angle $\gamma$ (Figure 1b), called the rolling angle of the work roll. The direction of their rotation is consistent. Figure $\mathbf{2}$ shows the view of an oblique extension mill.

a)

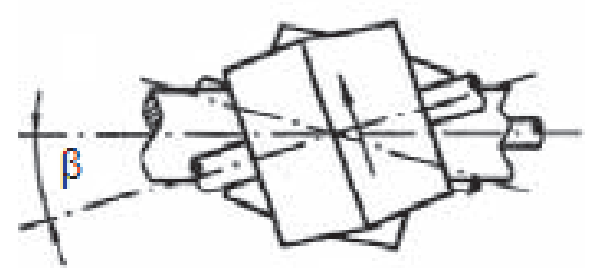

b)

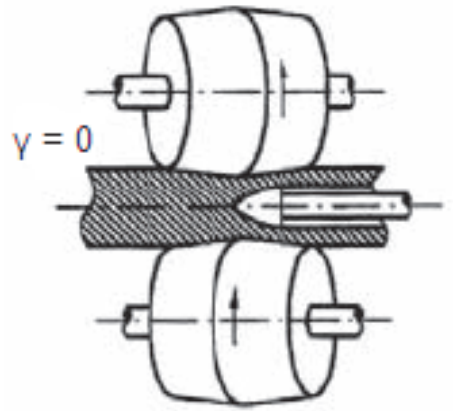

Figure 1 Diagram of the roll arrangement in an oblique extension mil [3]

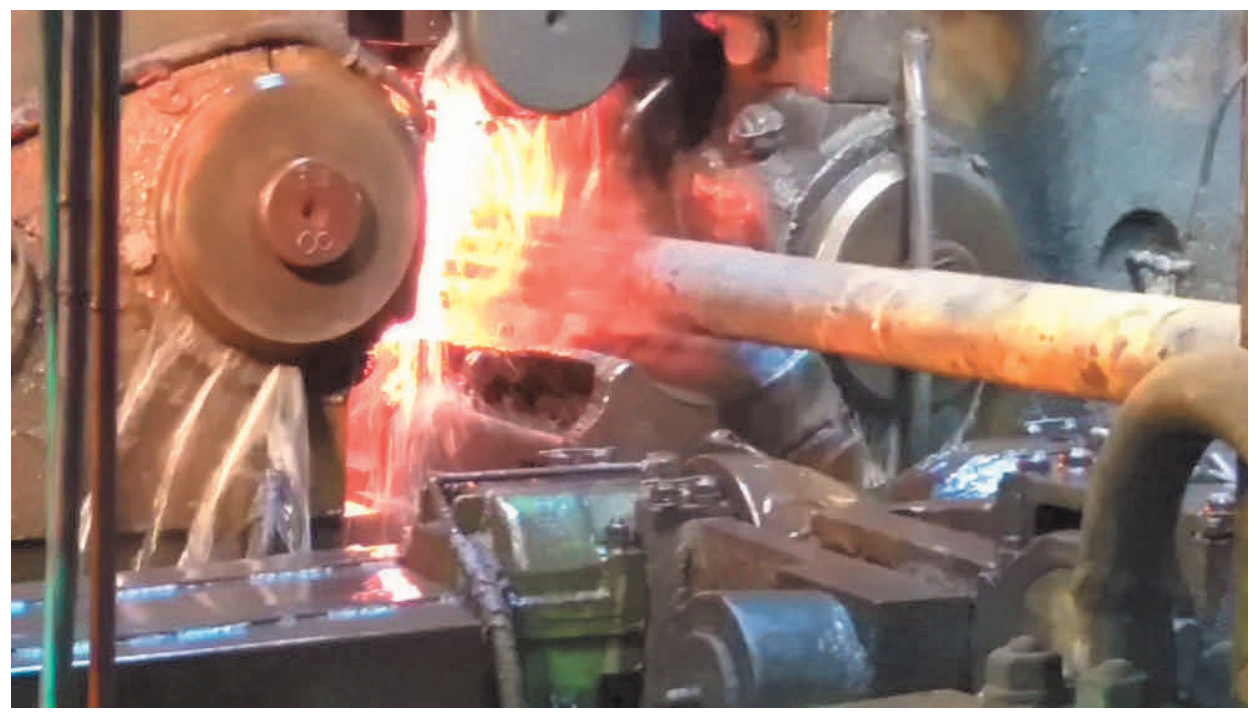

Figure 2 View of an oblique extension mill

During this process, a thick-walled bottomless sleeve is fed through the opening towards the deformation zone. It is followed by pulling it through the rollers into the deformation zone between the rollers and the rolling pin. At the end, the bottom of the sleeve is perforated and fully rolled. A characteristic feature of the rollers is their profile. Between the conical parts of the cylinder there is a rounded offset called a protrusion or sill that works with the head and causes a significant reduction in the wall thickness of the elongated sleeve. The deformation is given in the conical part of the rollers. The biggest deformation occurs at the protrusion (threshold) of the rolls. The shape of cylinders and punching head affects a more even distribution of metal pressure on the roller journals, reducing the negative axial slip of the metal, obtaining a sleeve with a more even outer diameter and wall thickness along its entire length, which leads to an elongated sleeve intended for further plastic processing in a pilgrim mill $[1,2]$.

On the basis of technical documentation and industrial analysis, it was concluded that it is possible to adjust the settings of the rolling mill. Appropriate selection of many interdependent parameters allows you to control the flow of material in the deformation basin and the quality of the raw pipe (after the pilgrim mill). 
Figures 3 and $\mathbf{4}$ show photos of the end parts of pipes with the same geometrical parameters after pilgrim rolling, for which the batch material was rolled in a slant rolling mill at different process parameters. On the basis of the shape analysis of the pipe, it can be stated that it is possible to control the settings of the rolling mill that ensures reduction of both technological waste and elimination of material discontinuity.

At present, modern methods of production of seamless tubes are based on high-efficiency processes. Existing assemblies consisting of a press and an extension roll were modified and replaced by a three-roll three-hole machine. Modifications to extension rollers have not been carried out for decades. Therefore, there are no results related to this issue in the literature. There are also rolling mills on the market that produce seamless pipes using pilgrimage methods, for which the elongation step in slant mills is very important.

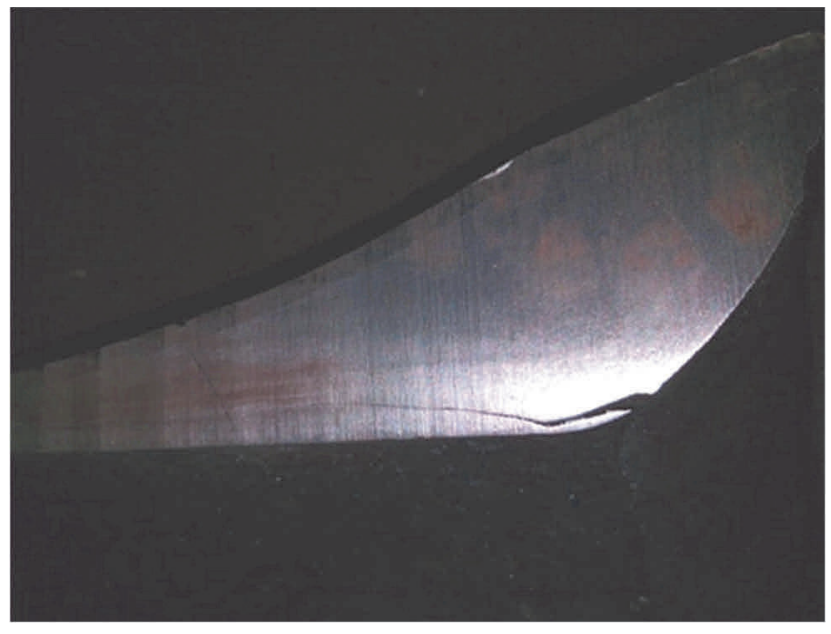

Figure 3 The part of the pipe bell after rolling in a pilgrim mill with a standard settings of rolling mill rolls, a visible defect inside the pipe bell

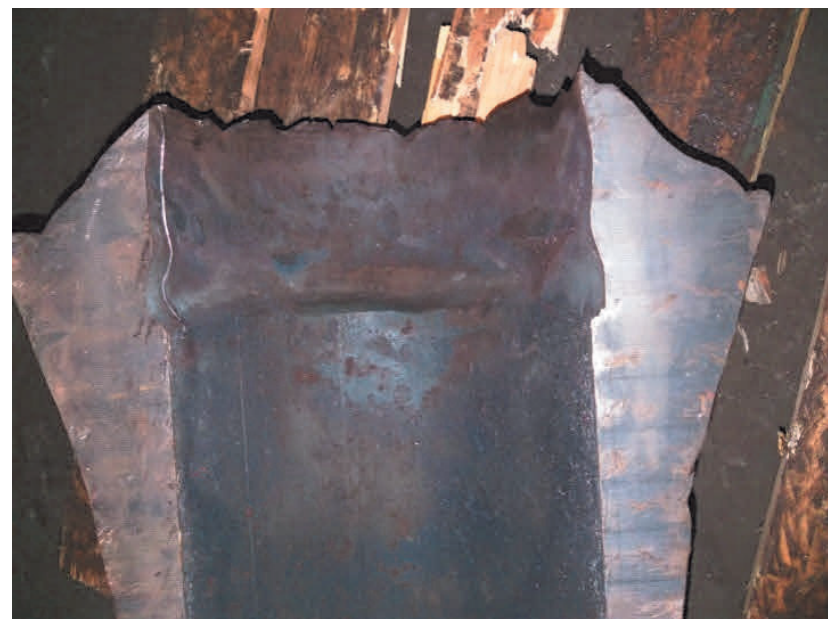

Figure 4 The part of the pipe bell after rolling in a pilgrim mill with changed settings of the rolls of the rolling mill

This type of research is equally cost-intensive and precise. [4,5] The application of software based on finite element methods (FEM) will allow for numerical modeling of the pipe rolling process and the process's impact on its quality.

\section{NUMERICAL MODELING OF ROLLING PROCESS}

In order to model the real conditions of the rolling process, theoretically three-dimensional issues of deformation should be analyzed, which is the basis for the design of rolling technology using computer modeling. It is also important to determine the influence of various settings of the elongated slanting mill on the flow behavior of the deformed material [6,7]. For this purpose, a three-dimensional geometric model of the rolling mill and the thick-walled sleeve was developed. The simulations were carried out for real rolling conditions of a $250 \mathrm{~mm}$ diameter raw pipe, and as a charge for a pilgrim mill, a thick-walled sleeve rolled in an extension mill with the diameter of $343 \mathrm{~mm}$ and the length of $2,400 \mathrm{~mm}$ from a perforated stock on a hydraulic press. Figure 5 shows the geometric model of the analyzed process. The species S235 was chosen as the material for which the coefficients describing its rheological parameters were taken from the FORGE 2.1 NxT database. Rolling was carried out for the rolling angle of $y=3^{\circ}$, and for the two extreme possible angles of beveling $\beta_{1}=3^{\circ}$ and $\beta_{2}=5^{\circ}$. A uniform temperature distribution in the stock was assumed, and at the beginning of rolling $1180^{\circ} \mathrm{C}$ was assumed. Industrial research has shown a significant effect of the size of the position of punch beyond the threshold of the rolls in the shape of a thick-walled sleeve. During theoretical 
considerations, roll assemblies were modeled, taking into account the variable position of punch in relation to the place where the deformation gap is the smallest.

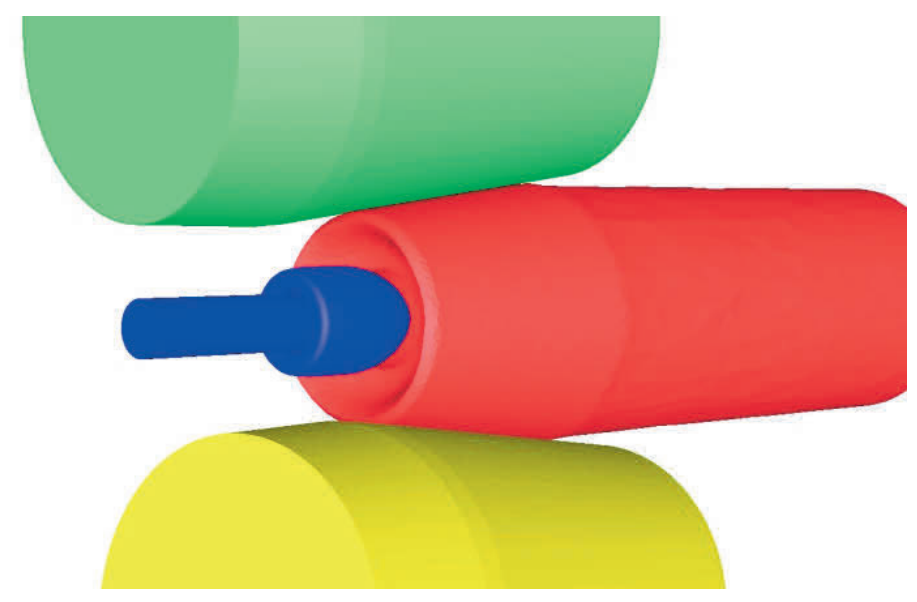

Figure 5 Geometric model of the rolling mill

On the basis of computer simulation, deformation distributions and strain rates distribution were obtained during the process, which are shown in Figures $\mathbf{6 a}$ and $\mathbf{6} \mathbf{b}$. The data presented in the figures show that the deformations of the material differ depending on the setting of the bevel of the working roll. Along with the increase of the beveling angle, the roll gap is shortened. This increases the strain intensity and can affect the geometry of the blank. Since rolling in a pilgrim mill takes place on a mandrel, the internal shape of the rolled sleeve is less important from the point of view of the entire process. Such a method of rolling will entail changes in energy and strength parameters.
a) $\beta=5^{\circ}$
b) $\beta=3^{\circ}$
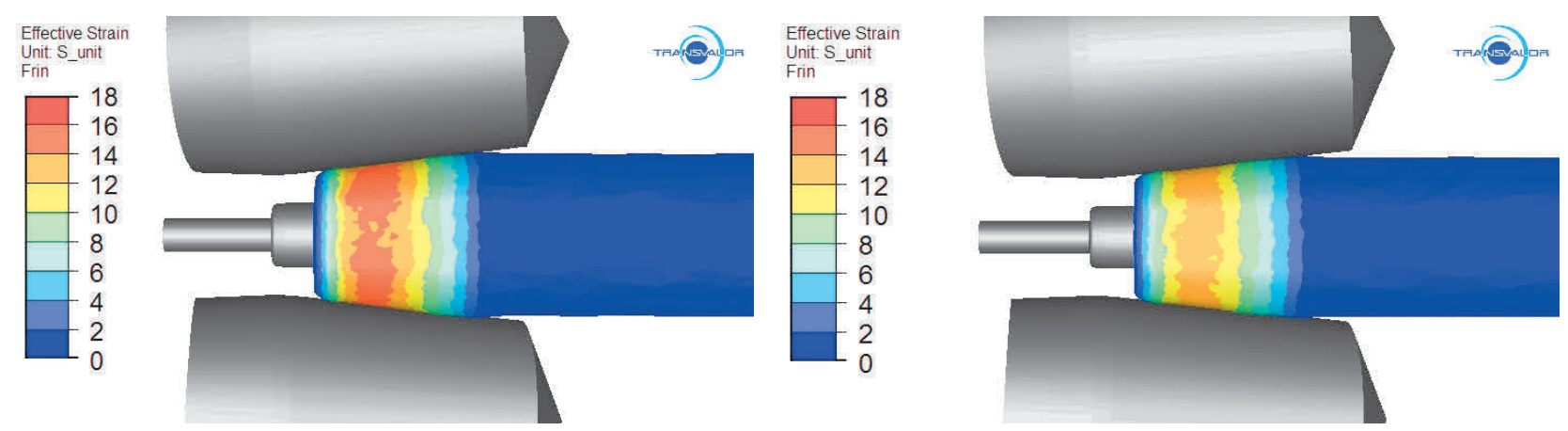

Figure 6 Deformation distributions were obtained during the process (on the surface)

Based on the analysis of the deformation distributions shown in Figures $7 \mathbf{a}$ and $\mathbf{7 b}$, it can be concluded that increasing the bevel angle increases the deformation value in cross-section, which can lead to the expanded shape of the sleeve, which affects the greater elongation of the outer layers compared to the inner ones. This may result in the rolling of the bottom residue shown in Figure 3.

Figures $\mathbf{8 a}$ and $\mathbf{8 b}$ show the distribution of strain rate in cross-section for two variations of the beveling angle. The analysis of the intensity of strain rate allows to conclude that the change in the beveling angle change the character of strain rate distribution and the shortening of the rolling gap. In addition, a larger accumulation of material was observed in front of the deformation gap, which may increase the total rolling pressures. The next 
stage of numerical research will be looking for settings rolls values angles for increase rolling direction flows of interior layers of metal and their influence on total pressure.
a) $\beta=5^{\circ}$
b) $\beta=3^{\circ}$
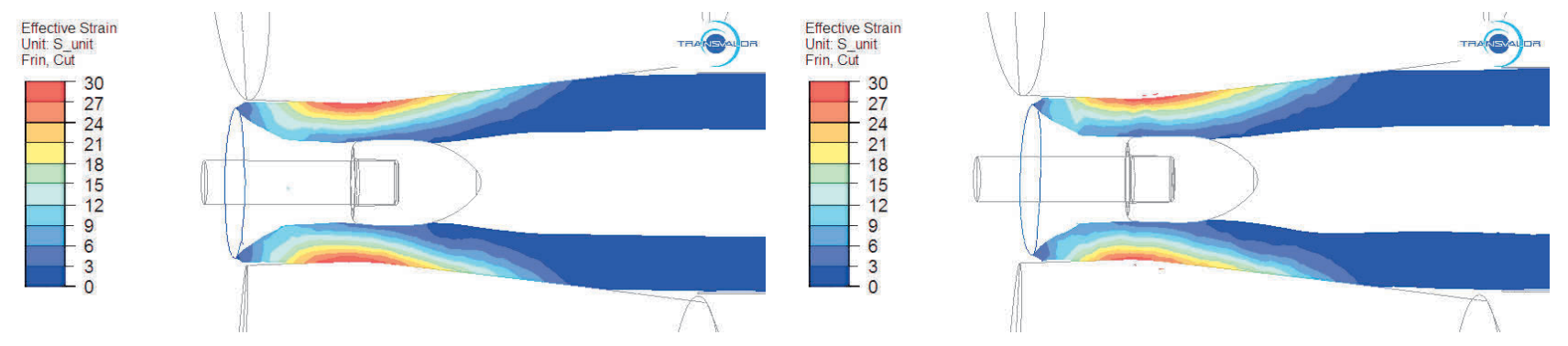

Figure 7 Deformation distributions were obtained during the process (in cross-section)

a) $\beta=5^{\circ}$

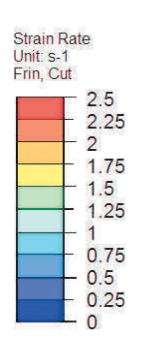

b) $\beta=3^{\circ}$

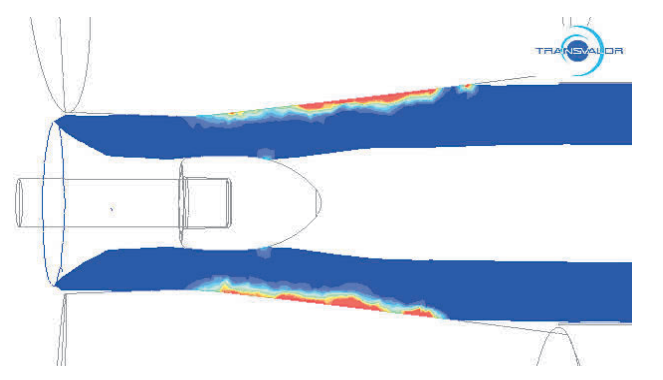

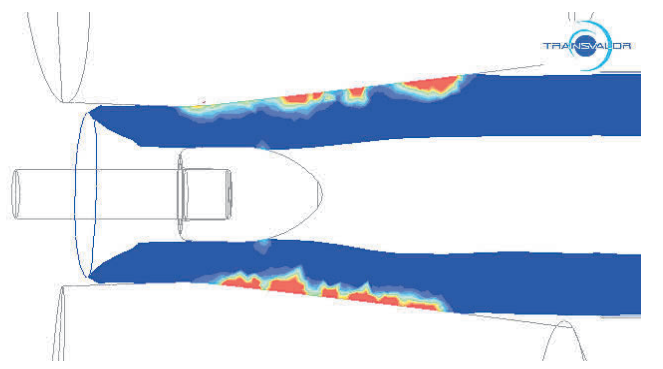

Figure 8 The distribution of strain rate (in cross-section)

\section{CONCLUSION}

Rolling of seamless pipes by pilgrim method with the use of elongation mill is a complicated process. The FEM analysis shows that changing one of the parameter settings significantly affects the deformation, strain rate, pressure force and energy consumption, as well as the quality of the finished pipe. Proper selection of these parameters enables control of the flow of material in the deformation gap. With the increase of the extension of the punching head beyond the narrowing of the work rolls, the length of the punching zone is shortened. The deformation zone between the working tools is reduced because of punching head with the increasing diameter enters the constant zone of the smallest gap between the rollers, making a greater reduction of the wall thickness of the sleeve. This affects one of the most important process parameters, i.e. the actual elongation factor. The size of the head place also has an indirect influence on such geometrical parameters of the deformation zone as the width of the contact surface of the deformed metal with the work roll and the total metal contact area. Further research will be carried out in the direction of determining the "optimal" angle of chamfering of work rolls and positioning of the punching head.

\section{REFERENCES}

[1] KAZANECKI, J. Wytwarzanie rur bez szwu. Kraków: Uczelniane Wydaw. Nauk.-Dydakt. AGH im. S. Staszica, 2003.p. 621.

[2] KAZANECKI, J., KAJTOCH, J. and KUBIŃSKI, W. Parametry kinematyczne walcowania tulei rurowych w walcarce wydłużającej (alongator) dwuwalcowej i trójwalcowej. Hutnik. 1977. vol. 44, no. 5, pp. 229-233.

[3] PENKAŁA, P. Metodologia pomiarów istotnych parametrów walcowania skośnego. Pomiary Automatyka Robotyka. 2011. no. 2, pp.792-799. 
[4] KNAPIŃSKI, M., KOCZURKIEWICZ, B., KAWAŁEK, A., GARSTKA, T. and KWAPISZ, M. The analysis of preliminary rolling process of X80 / X100 plates in laboratory conditions. In METAL 2014: 23rd International Conference on Metallurgy and Materials. Ostrava: TANGER, 2014, pp. 708-712.

[5] LANGE, K. Modern metal forming technology for industrial production. Journal of Material Processing Technology. 1997. no. 71, pp. 2-13.

[6] LABER, K. Influence of the Strain History, Strain State and Strain Rate on the Flow Stress, Microstructure and Mechanical Properties of the 30MnB4 Steel Grade During Physical Modeling of the Bar Rolling Process. Hutnik. 2016. vol. 83, no. 5, pp. 232-237.

[7] PIETRZYK, M., MADEJ, Ł., RAUCH, Ł. and SZELIGA, D. Computational Materials Engineering: Achieving high accuracy and efficiency in metals processing simulations. Waltham: Butterworth-Heinemann Elsevier, 2015. p. 380. 